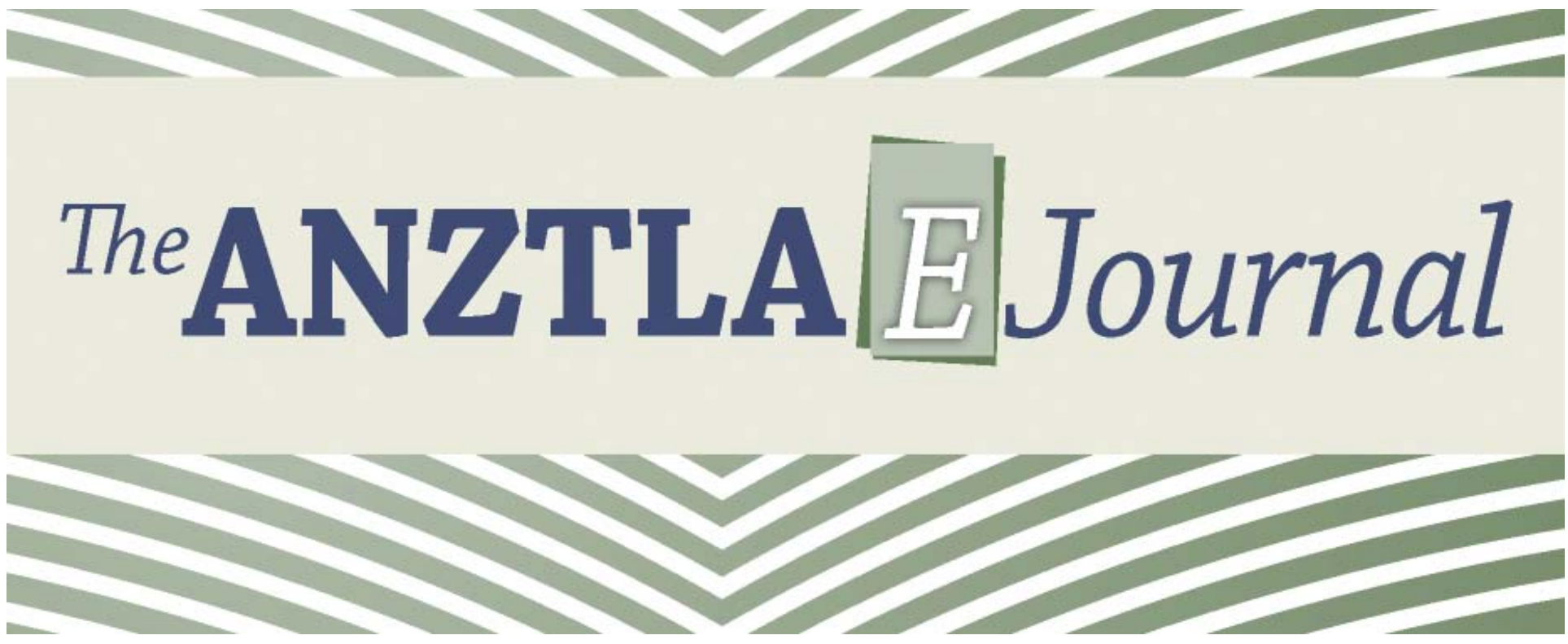

Australian and New Zealand Theological Library Association W No. 6 (2011)

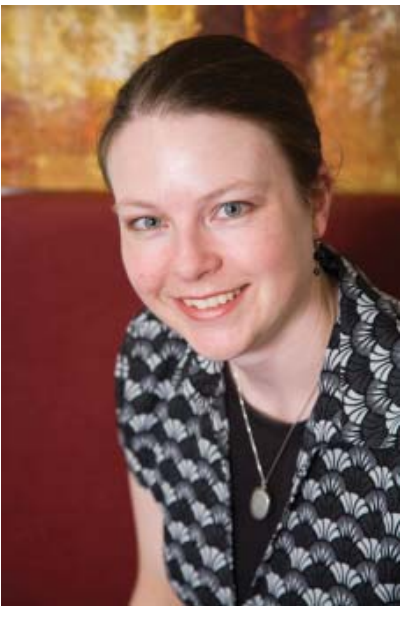

\section{Kerrie Stevens}

ANZTLA Statistician

Harvest Bible College

Waverly Gardens, Victoria
W elcome to the sixth issue of The ANZTLA EJournal the official serial publication of the Australian and New Zealand Theological Library Association.

It is possible to draw a number of analogies between stocktakes and dental appointments. They are necessary, but not always welcome. When these occur on a regular basis, there is less to fear and a better condition is maintained. There are some people who relish the experience! Kerrie Stevens is one of these. Her article, Taking Stock - The Process and Benefits of Performing a Regular Library Stocktake, provides inspiration and encouragement to those of us who might be wary of starting the process or who need to adopt a more regular practice.

In a previous issue of The ANZTLA EJournal, Kerrie reported on the use of statistics to 'measure, assess and evaluate the performance of libraries and their contributions to teaching, learning, research and their communities'. Here she presents the 2010 ANZTLA statistics.

\section{Eve James}

Editor

2 Taking Stock - The Process and Benefits of Performing a Regular Library Stocktake

$7 \quad$ ANZTLA 2010 Statistics 